\title{
Use of a management plan for treating asthma in an emergency department
}

\author{
I Town, T Kwong, P Holst, R Beasley
}

\begin{abstract}
A standardised management protocol has been developed for the assessment and treatment of adults with acute asthma attending an emergency department. The management protocol consists of an assessment sheet for recording essential features of the history and examination findings and a flow diagram with guidelines for initial management that were based on spirometric recordings. The protocol was introduced at Wellington Hospital in 1986. The effect of this intervention was assessed by analysing emergency department records during the three months before and one year after the introduction of the protocol. The use of the assessment sheet improved history taking and led to the increased use of serial measures of airflow obstruction and improved documentation of follow up arrangements. The provision of management guidelines influenced the emphasis of management, including an increased use of corticosteroids intravenously and more frequent use of an additional dose of nebulised bronchodilator. In the light of the initial experience the protocol has been modified and its use either in an emergency department or in general practice is recommended.
\end{abstract}

It is important that high standards of care for patients with asthma are established in emergency departments. In New Zealand the emergency department is used increasingly as a primary care facility for the treatment of asthma. ${ }^{1-3}$ Recent studies from the United Kingdom reviewing the management of patients attending emergency departments have noted deficiencies in assessment and management, including failure to perform respiratory function measurements, inadequate use of corticosteroids, over-reliance on beta agonist bronchodilators, and failure to make adequate follow up arrangements. ${ }^{4-6}$

In a recent review of asthma management in the emergency department at Wellington Hospital we also identified problems, including inadequate history taking-especially the identification of high risk symptoms such as nocturnal awakening or previous life threatening attacks-and poor communication with general practitioners when the patient is discharged from the department. ${ }^{3}$ In contrast to practice in the United Kingdom, however, respiratory function was measured in most patients and such recordings appeared to influence decisions about management.

In response to these problems we have devised and implemented an assessment and management protocol for the Wellington Hospital emergency department. The aim of the protocol was to provide guidelines for junior staff in the assessment and initial treatment of patients with acute asthma. The essential feature of the plan was the use of spirometric recordings as the basis for decisions on management. In this paper we report the effects of the protocol one year after its introduction.

\section{Methods}

THE MANAGEMENT PROTOCOL

The management protocol consisted of an assessment sheet (fig 1) and guidelines for initial management in the form of a flow diagram (fig 2). The assessment sheet was printed on self carbonising paper. One copy was retained in the emergency department records and the other accompanied the patient, whether he or she was admitted to or discharged from hospital. Medical officers were fully briefed by one of us at an orientation session held before their rotation into the emergency department. During this briefing the rationale for the use of forced expiratory volume in one second $\left(\mathrm{FEV}_{1}\right)$ as the basis for management decisions was explained, and advice was given about drug administration and the need for consultation with senior staff in difficult cases.

\section{ASSESSMENT}

We carried out a retrospective analysis of emergency department records covering three months at Wellington Hospital (catchment population of 200000 ) before (1986) and one year after (1987) the introduction of the protocol. All patients aged 15-70 years presenting to the emergency department with asthma were included in the study. Data on all visits were analysed, including return visits and visits by patients requesting a bronchodilator prescription only. Demographic details, asthma history, examination findings, respiratory function, details of treatment, and evidence of communication with general prac- 
ASTHMA ASSESSMENT SHEET

(To be placed in the accident and emergency department (A \& E card); copy with patient)

\begin{tabular}{|l|l|}
\hline Name & \\
\hline Hospital number & \\
\hline Name of GP \\
\hline
\end{tabular}

\begin{tabular}{|l|l|}
\hline Date & \\
\hline Time of arrival & \\
\hline
\end{tabular}

\section{Asthma History}

\begin{tabular}{|l|l|l|}
\hline $\begin{array}{l}\text { Duration of } \\
\text { current attack }\end{array}$ & \multicolumn{2}{|l|}{} \\
\hline $\begin{array}{l}\text { Number of attacks in } \\
\text { previous } 12 \text { months }\end{array}$ & \\
\hline $\begin{array}{l}\text { Previous ICU } \\
\text { admission }\end{array}$ & Yes (tick) & \\
\hline & No & \\
\hline $\begin{array}{l}\text { Use of } \\
\text { corticosteroids }\end{array}$ & $\begin{array}{l}\text { Previous courses } \\
\text { of prednisone }\end{array}$ & \\
\cline { 2 - 3 } & $\begin{array}{l}\text { Maintenance } \\
\text { prednisone }\end{array}$ & \\
\hline
\end{tabular}

Usual Medication (dose and frequency)

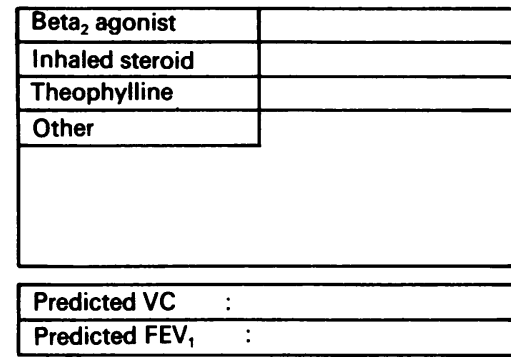

Progress Record

\begin{tabular}{|l|l|l|l|}
\hline Data & Initial assessment & After 15 min & Final assessment \\
\hline Time & & & \\
\hline Pulse rate & & & \\
\hline FEV litres & & & \\
\hline \multicolumn{1}{|c|}{ predicted } & & & \\
\hline Treatment given & & & \\
\hline
\end{tabular}

Inhaler technique checked: Satis / Poor

Comments

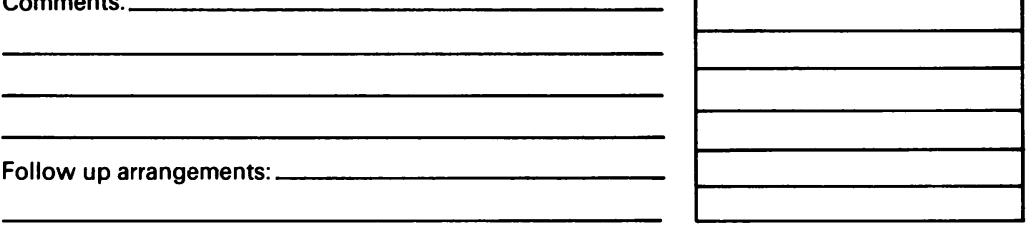

Casualty officer's name

Figure 1 Asthma assessment sheet used until 1988 for the recording of asthma history, medical assessment including results of spirometry, discharge medications, and follow up arrangements. ICU-intensive care unit.

\section{GUIDELINES FOR THE INITIAL MANAGEMENT OF ASTHMA}

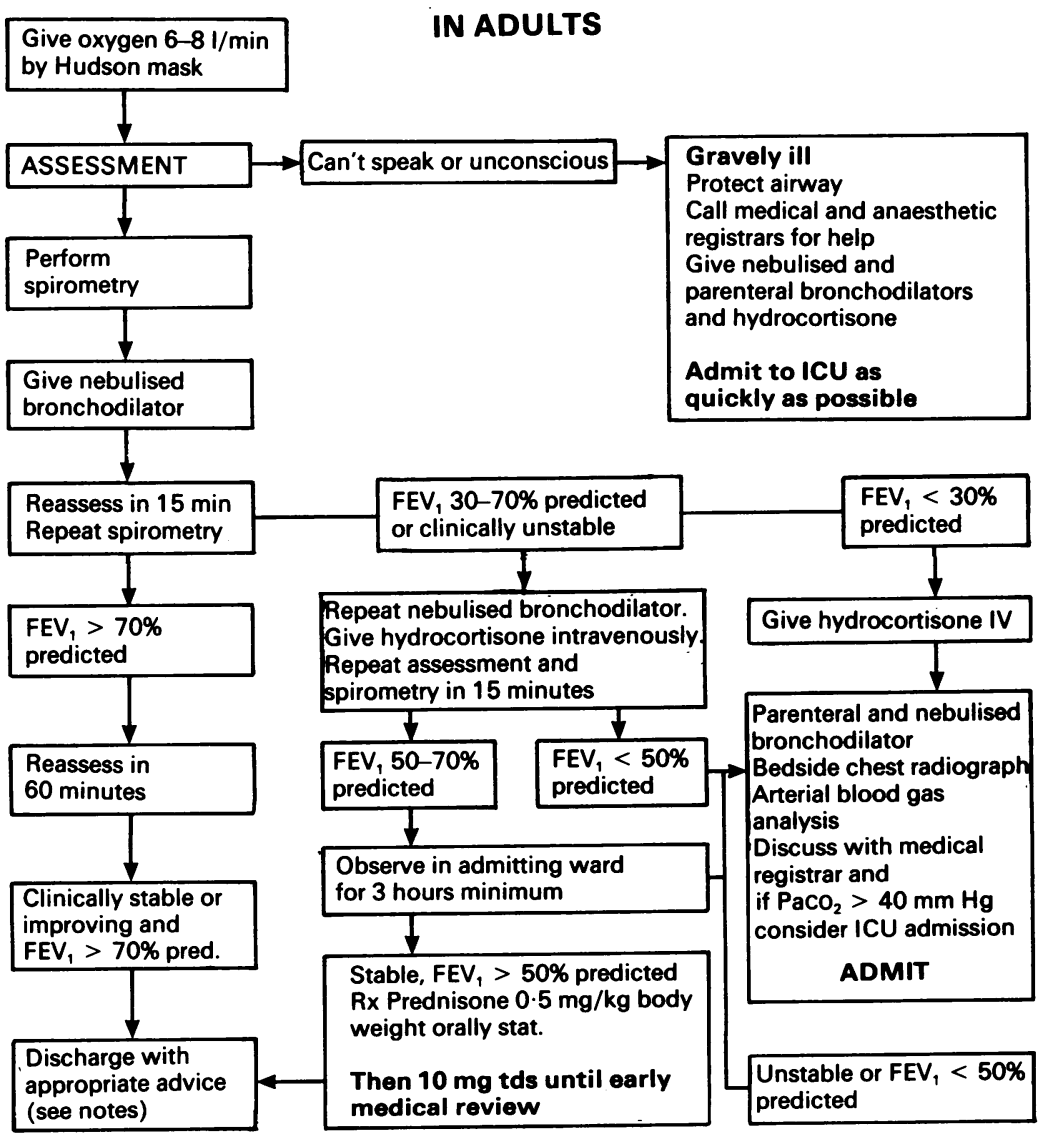

Figure 2 Flow diagram giving guidelines for the initial treatment of adult patients with asthma before 1988 . Management was based on FEV values taken before and after initial bronchodilator treatment. It was accompanied by notes on drug dosages, discharge criteria, and follow up arrangements.
Table 1 Characteristics of patients attending the emergency department

\begin{tabular}{lll}
\hline & \multicolumn{2}{l}{ No $(\%)$ of patients } \\
\cline { 2 - 3 } Characteristic & 1986 & 1987 \\
\hline Patients attending & & \\
$\quad$ At weekend & $33(27)$ & $51(37)$ \\
1600-0800 hours & $87(71)$ & $100(73)$ \\
Seen by general practitioner & $12(10)$ & $14(10)$ \\
Requesting prescription only & $13(11)$ & $12(9)$ \\
Patients discharged & & \\
Documented follow up & & \\
$\quad$ arrangement & $28(23)$ & $67(49)^{\star}$ \\
$\quad$ Prescribed prednisolone & $43(35)$ & $64(47)$ \\
Reattendance within one month & $13(11)$ & $12(9)$
\end{tabular}

Significance of differences $\left(\chi^{2}\right.$ test $):{ }^{\star} p<0.01$.

titioners were extracted and encoded on a database program (Microsoft Excel) for analysis. The significance of differences between the two years was assessed by the $\chi^{2}$ test.

Results: changes in practice after introduction of the protocol

The numbers of attendances during the two three month study periods were similar (122 in 1986 versus 137 in 1987). Most patients were self referred and attended between 1600 and 0800 hours. There were no major differences in the demographic characteristics of the two groups (table 1).

\section{EXTENT OF DOCUMENTATION}

The assessment sheet provided spaces for recording routine asthma treatment and previous admissions to the intensive care unit, and these features of the history were documented in most cases after implementation of the protocol (table 2). A history of recent hospital admission or nocturnal wakening, which did not have a place on the assessment sheet, was obtained from a few patienț during both study periods.

The only examination finding required on the assessment sheet was the pulse rate (fig 1) and this was recorded in most cases in both 1986 and 1987 (table 2). Measurement of

Table 2 Extent of documentation: numbers and percentages of patients in whom history variables, examination findings, and respiratory function results were recorded

\begin{tabular}{lcc}
\hline & \multicolumn{2}{l}{$N o\left({ }^{o}{ }_{o}\right)$ of patients } \\
\cline { 2 - 3 } Variable recorded & 1986 & 1987 \\
\hline Routine treatment & $105(86)$ & $132(96)$ \\
Previous intensive care unit & & \\
$\quad$ admission & $9(7)$ & $110(80)^{\star}$ \\
Recent hospital admission & $48(39)$ & $62(45)$ \\
Nocturnal symptoms & $1(1)$ & $1(1)$ \\
Pulse rate & $112(92)$ & $126(92)$ \\
Arterial paradox & $61(50)$ & $34(25)^{\star}$ \\
Auscultation of chest & $112(92)$ & $77(56)^{\star}$ \\
FEV before treatment & $46(38)$ & $116(85)^{\star}$ \\
PEF before treatment & $93(76)$ & $10(7)^{\star}$ \\
Either FEV or PEF before & $102(84)$ & $121(88)$ \\
$\quad$ treatment & $22(18)$ & $27(20)$ \\
Arterial blood gas measurement & $32(26)$ & $115(84)^{\star}$ \\
FEV ${ }_{1}$ after treatment & $73(60)$ & $5(4)^{\star}$ \\
PEF after treatment & $84(69)$ & $116(85)^{\star}$ \\
Either FEV ${ }_{1}$ or PEF after & & \\
$\quad$ treatment & &
\end{tabular}

Significance of differences $\left(\chi^{2}\right.$ test $):{ }^{\star} p<0.01$.

FEV - forced expiratory volume in one second; PEF-peak expiratory flow. 
ASTHMA ASSESSMENT SHEET

(To be placed in the accident and emergency department ( $A \& E$ ) file; copy with the patient)

\begin{tabular}{|l|l|}
\hline Name & \\
\hline A\&E Ref No & \\
\hline GP name & \\
\hline Date & \\
\hline
\end{tabular}

Asthma History

\begin{tabular}{|l|l|}
\hline Duration of attack & \\
\hline Admission in last 12 months & Yes / No \\
\hline Steroids in last 12 months & Yes / No \\
\hline Nocturnal symptoms & Yes / No \\
\hline
\end{tabular}

Usual Medications (Dose and frequency)

\begin{tabular}{|l|l|}
\hline Bronchodilator & \\
\hline Inhaled steroid & \\
\hline Theophylline & \\
\hline Other & \\
\cline { 1 - 2 } &
\end{tabular}

Other

Predicted FEV $_{1}$

Progress Record

\begin{tabular}{|l|l|l|l|}
\hline Data & Initial assessment & Further assessment & Final assessment \\
\hline Time & & & \\
\hline Pulse rate & & & \\
\hline FEV litres/second & & & \\
\hline $\begin{array}{l}\text { Treatment given } \\
\text { in A\&E department }\end{array}$ & & & \\
& & & \\
& & & \\
\hline
\end{tabular}

Disposal

\begin{tabular}{|l|l|}
\hline Admitted & Ward \\
\hline Discharged & Time \\
\hline Inhaler technique & Good / Poor \\
\hline Date to see GP & \\
\hline
\end{tabular}

Name of A\&E Medical Officer

Figure 3 Revised assessment sheet.

\section{GUIDELINES FOR THE INITIAL MANAGEMENT OF ASTHMA}

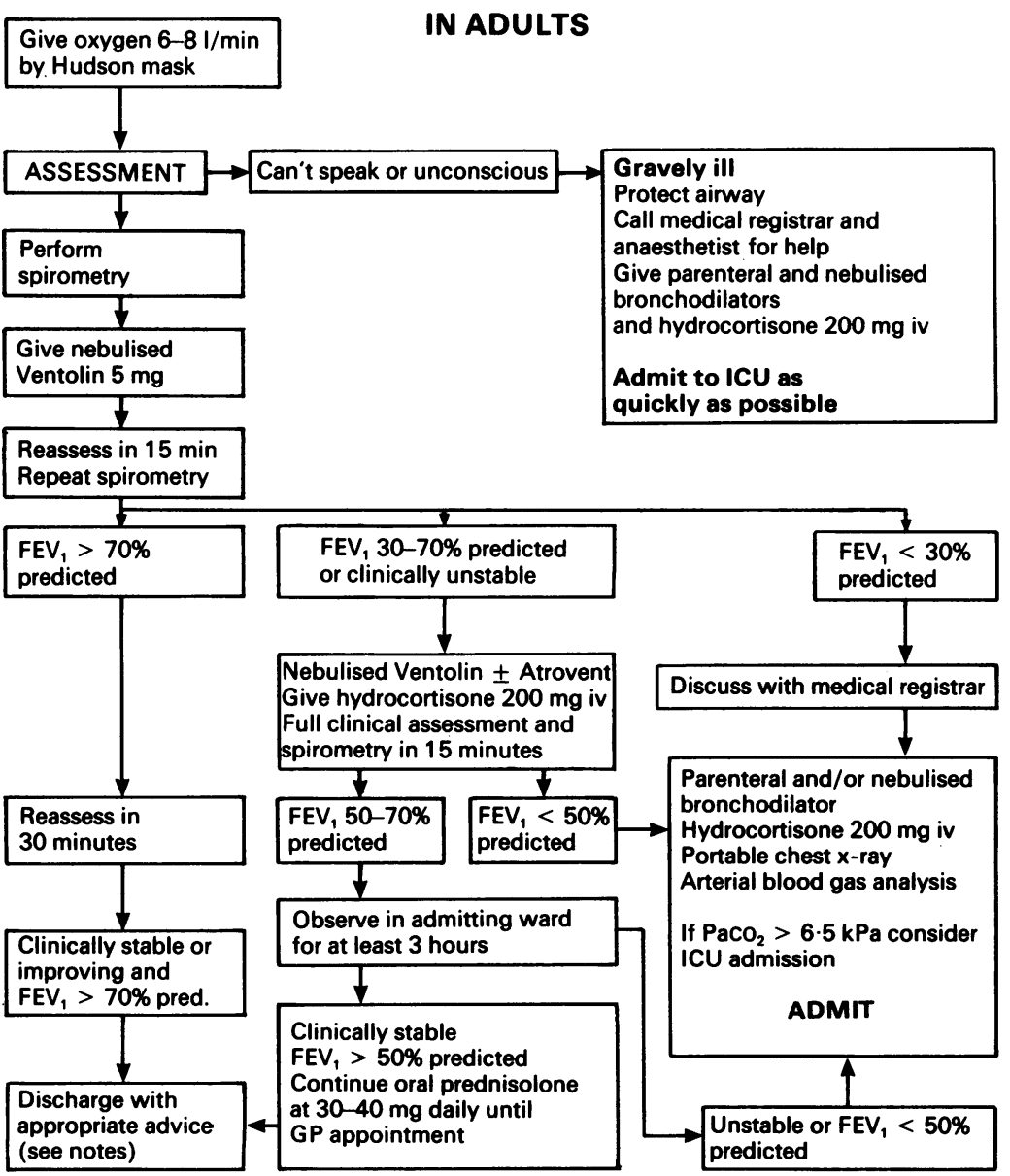

Figure 4 Revised treatment flow diagram. ICU-intensive care unit. systolic blood pressure paradox and auscultation of the chest were recorded in significantly fewer cases after introduction of the protocol.

In both years most patients had respiratory function measured before initial bronchodilator treatment (table 2). In 1986 most had peak expiratory flow (PEF) documented whereas in 1987, in response to the change in policy, most had forced expiratory volume in one second $\left(\mathrm{FEV}_{1}\right)$ measured. After implementation of the protocol more patients had a repeat measurement made after their initial treatment.

\section{MANAGEMENT}

The institution of specific guidelines for the management of asthma resulted in a change in the emphasis of treatment. In 1987 more patients were given intravenous corticosteroids (36\% in $1986 v 61 \%$ in 1987; p < 0.01) and an additional dose of nebulised bronchodilator $(25 \%$ in $1986 v 60 \%$ in 1987; $\mathrm{p}<0.01)$. The numbers of patients receiving aminophylline intravenously (20\% in $1986 v 27 \%$ in 1987) were not significantly different.

In 1987 follow up arrangements were documented in a greater proportion of patients discharged from the emergency department and there was a trend towards prescription of a course of oral corticosteroids for more patients at the time of discharge (table 1). In 1987 only one patient with an $\mathrm{FEV}_{1}$ below 1.51 was discharged without being given a course of corticosteroids. Comparison with 1986 was not possible as $\mathrm{FEV}_{1}$ or PEF was seldom recorded at the time of discharge.

\section{OUTCOME}

The hospital admission rate was similar for 1986 and 1987 (34\% $v 36 \%$ ). Among those discharged the relapse rate, as assessed by a return visit to the emergency department within one month, was similar during the two periods (table 1 ).

\section{Discussion}

This study shows that the assessment and management of patients presenting to the emergency department with asthma can be modified by introducing a standardised protocol. The provision of a form for recording essential features of the history and examination findings and guidelines for treatment based on the objective assessment of airflow obstruction provided the means to establish standards of care that are consistent with current recommendations. ${ }^{78}$

In the two three month periods we studied the demographic characteristics of the sample populations were similar. As has been previously noted, hospital emergency departments in New Zealand often provide primary medical care for the treatment of severe asthma, most patients who attend being self referred..$^{1-39} \mathrm{It}$ is particularly important, if the emergency department is to have this role, that standards of management are high and that adequate follow up is instituted for all patients. Although there is also a trend for self referral in England, ${ }^{10}$ most patients see their general prac- 
titioners either at the onset of the attack or immediately before admission. ${ }^{6}$

It is now established that the assessment of asthma severity cannot be based on symptoms and signs alone but should include an objective measure of airflow obstruction such as PEF or FEV $_{1}{ }^{11-13}$ Such measurements enable both the patient and the attending medical practitioner to assess more accurately the severity of the asthma attack; failure to recognise a severe attack has consistently been identified as contributing to death from asthma, both in the community and in hospital..$^{14-16}$ Although we used $\mathrm{FEV}_{1}$ as the method of assessment, PEF would offer an acceptable alternative, particularly for general practice. A spirometer was provided for use in the emergency department and the medical staff were encouraged to measure the $\mathrm{FEV}_{1}$ in all patients presenting with asthma. Thereafter the flow sheet required further recordings to be made after initial bronchodilator treatment as the basis for subsequent decisions about further treatment and the need for hospital admission. After

\section{Guidelines for the initial management of asthma in adults (notes to accompany management protocol)}

\section{Nebulised bronchodilators}

Ventolin nebule $5 \mathrm{mg}$ nebulised using oxygen at $6-8 \mathrm{l} / \mathrm{min}$ until finished. If there is a poor response to initial nebulised treatment, repeat the Ventolin with the addition of an Atrovent $0.5 \mathrm{mg}$ nebule.

\section{Parenteral bronchodilator therapy}

$\begin{array}{ll}\text { 1. Salbutamol } & -4 \mu \mathrm{g} / \mathrm{kg} \text { stat by } \mathrm{iv} / \mathrm{im} / \mathrm{sc} \text { injection } \\ & - \text { infusion of } 3-20 \mu \mathrm{g} / \mathrm{min} \text { titrated according to } \\ & \text { the response }\end{array}$

\section{OR}

\section{Aminophylline}

- loading dose $5 \mathrm{mg} / \mathrm{kg}$ by slow intravenous injection

- reduce loading dose if patient has taken any theophylline within the last 24 hours

Maintenance infusion $-0.6 \mathrm{mg} / \mathrm{kg} /$ hour in healthy young adults $-0.4 \mathrm{mg} / \mathrm{kg} / \mathrm{hour}$ if $>65$ years or in the presence of liver/cardiac disease

- review dose once plasma level known

\section{Additional notes}

1. These are guidelines only and may not suit all patients. If there is any doubt about a particular patient discuss with the medical registrar. Admit any patient who is unstable, regardless of the FEV ${ }_{1}$.

2. Any patient who remains ill despite intensive treatment should have a chest radiograph to exclude a pneumothorax.

3. If the patient has pus in the sputum, consider antibiotic therapy (4 day course of Augmentin $500 \mathrm{mg}$ tds or tetracycline $250 \mathrm{mg}$ qid).

4. Some patients attend $A \& E$ frequently for the treatment of asthma. If difficult asthmatics are identified, consider referral to the chest clinic.

5. A patient discharged from the A\&E Department is not "cured." They must be sufficiently stable to continue with prescribed treatment and see their GP for follow up.

6. Those patients discharged on prednisone should take $30-40 \mathrm{mg}$ daily until review within a few days by their general practitioner.

7. Give the patient a peak flow meter and demonstrate its use.

The following minimum criteria should be satisfied before any asthmatic leaves A\&E

(a) The FEV, is stable and $>50 \%$ predicted.

(b) The patient can use a bronchodilator inhaler correctly and has access to other medications.

(c) The patient understands the need for follow up by his/her own general practitioner.

(d) The patient has a copy of the assessment sheet as a record of management. introduction of this policy most patients had their $\mathrm{FEV}_{1}$ measured both before and after initial treatment. Probably the introduction of management guidelines based on these serial measurements resulted in improved asthma treatment, such as the greater use of intravenous corticosteroids.

It was difficult to detect any change in outcome in patients discharged from the emergency department from the variables assessed. The reattendance rate for patients discharged from the department within a month of their initial visit was low before introduction of the protocol and did not change significantly. This contrasts with the experience in the United States, where relapse rates of up to $25 \%$ have been reported. ${ }^{1718}$ We might reasonably assume, however, that the improved communication with the general practitioner and greater use of corticosteroids at discharge represents an improvement in overall management.

One of the limitations we observed with our protocol was that only those history and examination variables specified on the form were documented regularly. Thus routine asthma treatment and previous intensive care unit admission were documented in almost all cases after introduction of the protocol, whereas other important symptoms, such as recent hospital admission and nocturnal wakening, were seldom recorded. Examination of blood pressure paradox and auscultation of the chest were performed less commonly after the introduction of the protocol for the same reasons. When protocols such as this are developed all features of the history and examination that are considered relevant should be included.

In summary, we have examined the use of a standardised assessment and treatment protocol for the management of asthma within a hospital emergency department. Despite some problems with the initial protocol we found that it resulted in a high standard of care and would recommend its use. Such a protocol could be implemented both in general practice and in other emergency departments after modification to comply with local management practices.

\section{Modifications to the protocol}

After experience with our initial management plan several changes have been implemented. We have introduced space for recording nocturnal awakening and admission to hospital within the previous year on the assessment sheet (fig 3) as these are important signs of unstable asthma associated with an increased risk of death. ${ }^{19-21}$ For the treatment guidelines (fig 4) a fuller clinical assessment is requested at the time of the repeat spirometry and early consultation with the medical registrar is suggested for patients with severe asthma.

The other important changes are in the discharge recommendations (fig 5). All patients are given a peak flow meter. After discharge those requiring prednisone are prescribed 30-40 mg daily until review within a few days by their general practitioner. Finally, as a result

Figure 5 Notes to accompany the treatment flow diagram. 
of the New Zealand Department of Health's recommendations advising against the use of fenoterol in patients with severe asthma, Duovent was deleted from the protocol and ipratropium bromide (Atrovent) is available when a further nebulised bronchodilator is required.

We acknowledge Drs P Rothwell and B Mahood for suggesting the use of such protocols, Dr $\mathrm{H}$ Leslie and the staff of the Wellington Hospital emergency department for their interest and cooperation, and the secretarial staff of the department of medicine.

1 Garrett JE, Mulder J, Veale A. Trends in the use of our urban accident and emergency departments by asthmatics. NZ Med J 1988;101:253-5.

2 Garrett JE, Mulder J, Wong-Toi H. Characteristics of asthmatics using an urban accident and emergency department. NZ Med J 1988;101:359-61.

3 Kwong T, Town I, Holst P, Beasley R. A New Zealand study of the management of asthma in a hospital emergency department. NZ Med J 1989;102:547-9.

4 Reed S, Diggle S, Cushley MJ, Sleet RA, Tattersfield AE Assessment and management of asthma in an accident and emergency department. Thorax 1985;40:897-902.

5 Ebden P, Carey OJ, Quinton D, Cookson JB. A study of acute asthma in the accident and emergency department. Br J Dis Chest 1988;82:162-7.

6 Bucknall CE, Robertson C, Moran F, Stevenson RD Management of asthma in hospital: a prospective audit. $\mathrm{Br}$ Med J 1988;i:1637-9.

7 Anonymous. Acute asthma [editorial]. Lancet 1986;i:131-3.

8 Tatham ME, Gelert AR. The management of acute severe asthma. Postgrad Med J 1985;61:599-606.
9 Glazebrook KN, Sutherland DC. Management of acute asthma attacks in Auckland A \& E departments. NZ Med J 1985;98:590-3.

10 Anderson HR, Bailey P, West P. Trends in the hospital care of acute childhood asthma 1970-8: a regional study. $B r$ Med J 1980;281:1191-4.

11 McFadden ER, Kiser R, De Groot WJ. Acute bronchial asthma. Relations between clinical and physiological manifestations. N Engl J Med 1973;288:221-5.

12 Rubinfeld AR, Pain MCF. Perception of asthma. Lancet 1976;ii:882-4.

13 Burdon JGW, Juniper EF, Killian KJ, Hargreave FE, Campbell EJM. The perception of breathlessness in asthma. Am Rev Respir Dis 1982;126:825-8.

14 Rothwell RPG, Rea HH, Sears MR, et al. Lessons from the national asthma mortality study: deaths in hospital. NZ Med J 1987;100:199-202.

15 British Thoracic Society. Death from asthma in two regions in England. Br Med J 1982;285:1251-5.

16 Rea HH, Sears MR, Beaglehole R; et al. Lessons from the national asthma mortality study: circumstances surrounding death. NZ Med J 1987;100:10-3.

17 Kelson SG, Kelson DP, Fleegler BF, Jones RC, Rodman T. Emergency room assessment and treatment of patients with acute asthma: adequacy of the conventional approach. Am J Med 1978;64:622-8.

18 Fischl MA, Pitchenick A, Gardener LB. An index predicting relapse and need for hospitalisation in patients with acute bronchial asthma. $N$ Engl J Med 1981;305:783-9.

19 Bateman JRM, Clarke SW. Sudden death in asthma. Thorax 1979;34:40-4.

20 Hetzel M, Clark TJH, Branthwaite M. Asthma-analysis of sudden death and ventilatory arrest in hospital. $\mathrm{Br}$ Med J 1977;i:808-11.

21 Rea HH, Scragg R, Jackson R, Beaglehole R, Fenwick J, Sutherland DC. A case-control study of deaths from asthma. Thorax 1986;41:833-9.

\section{BOOK NOTICES}

Platelet Activating Factor in Endotoxin and Immune Diseases. DA Handley, RN Saunders, WJ

Houlihan, JC Tomesch. (Pp 692; \$198.) New York: Dekker, 1990. ISBN 0-8247-8098-1.

To my knowledge, this is the fifth book on platelet activating factor (PAF) to have been published recently-perhaps a reflection of the growing interest in this mediator in various disease processes. This book is a collection of 34 chapters from different research groups on current trends in PAF research and concentrates mostly on the use of PAF antagonists in a wide ranging number of animal models related to renal transplantation, pregnancy, endotoxaemia, ischaemic bowel necrosis, bronchial hyperresponsiveness, immune complex disease, and lung injury. Most contributors present a summary of their own data, and very often parallel findings are presented, resulting in an overlap of information. What is lacking in this 700 page book is authoritative chapters that provide a rapid overview and synthesis of several specific areas. This would have been particularly helpful for those who want to learn about PAF. As PAF is now considered to be particularly concerned in modulation of cell to cell interactions, I was disappointed to find only one slim chapter in this growing area. The first chapter, by Dr Benveniste, is the most interesting one with a highly personalised account of the discovery and synthesis of PAF. Perhaps an American contribution in this area would have restored the balance. At $£ 125$, this book will most likely find its way on the shelves of some pharmacological libraries. It would be useful for those who already have some research interest in PAF as a source of reference and information. For the novice or pulmonary physician, it is well worth a browse.-KFC
Pediatric Intensive Care. 2nd ed. Eliezer Nussbaum. (Pp 964; \$150.) New York: Futura, 1989. ISBN 087993-343-7.

The number of good comprehensive books on paediatric intensive care is limited, although many paediatricians are concerned to some extent in the care of critically il children. For this reason the new edition of Pediatric Intensive Care should be welcomed. The list of contributors is very impressive; all but two are from units in North America. Sadly, I found the result disappointing. New sections have been added, which are of considerable interest, but there seems to be little balance in the content and no logical organisation of the text. The original section was concerned with problems of the central nervous system. This is followed by a though provoking but unacceptably long section on the diagnosis of death and the ethics of intensive care, amounting to 100 pages. The next section, on acute cardiovascular disorders, is also patchy but there is an interesting section on new concepts of sepsis in children. The nex chapters are on intensive monitoring and respiratory failure. Again the balance seems odd, with only five pages and seven references on status asthmaticus, compared with 60 pages and 540 references on the adult respiratory distress syndrome. Other sections include trauma, bleeding and clotting disorders, infection, renal and endocrine disorders, gastroenterology, and foreign bodies. Forty pages are devoted to the sudden infan death syndrome and, again, much of this is devoted to the management of the child at home, which seems inappropriate in a book on paediatric intensive care. Finally, there are sections on clinical pharmacology and toxicology and on nursing aspects.

Although I think that this is a book that intensive care units caring for children will wish to have, I suspect that they will be selective in the way they refer to it. They will certainly find some sections disappointing and even rather out of date by European standards. This is a book to look at carefully before ordering.-ADM 